
upf. $\begin{array}{ll}\text { Universitat } & \text { Department } \\ \text { Pompeu Fabra } & \text { of Economics and Business }\end{array}$ Barcelona

Economics Working Paper Series

Working Paper No. 1696

\title{
Prospects of blockchain in contract and property
}

\author{
Benito Arruñada
}

January 2020 


\title{
Prospects of Blockchain in Contract and Property
}

This version: January 2, 2020

\author{
Benito Arruñada*
}

\begin{abstract}
Recurrent difficulties are delaying what for the time being are still modest applications of blockchain. This paper identifies what value this new technology adds to the contractual and property processes, exploring its potential and analyzing the main difficulties it is facing. Paying particular attention to the distinction between contract (personal or in personam) rights and property (real or in rem) rights, it first examines the difficulties for trading contract rights through blockchain-based applications, mainly those to complete contracts ex ante without relying on third-party enforcers. Second, it explores the difficulties faced by blockchain to enable trade in property rights.
\end{abstract}

Keywords: property rights, enforcement, transaction costs, impersonal exchange, blockchain, distributed ledgers, smart contracts, registries.

JEL: D23, K11, K12, L85, G38, H41, O17, P48.

\footnotetext{
* Pompeu Fabra University and Barcelona GSE. E-mail: benito.arrunada@upf.edu. This work, prepared for the Conference on "Disruptive Technology, Legal Innovation and the Future of Real Estate” at IDC Herzliya, 23-24 June, 2019, is a heavily revised version of Arruñada (2018) that deepens and updates both its theoretical and empirical analyses of blockchain applications in contract and property rights. This new version has greatly benefitted from the written comments of Fátima Antelo, Jesús Remón Peñalver and Rod Thomas to an earlier version. It received support from the Spanish Government through grant ECO2017-85763-R and the Severo Ochoa Program for Centers of Excellence in R\&D (SEV-2015-0563). Usual disclaimers apply.
} 


\section{Blockchain And Contract, In Personam, RIGHTS}

\section{A. Contract Completion in Smart Contracts}

Blockchain is now applicable not only to payments but to many types of contracts; thus, instead of exchanging digital tokens valuable by themselves and existing only in the blockchain ledger (such as Bitcoin), parties can exchange representations of claims in all types of physical or digital assets existing outside the ledger, even if the consequences of such exchange will often hinge, as we will see, on what courts consider the applicable law. Moreover, through systems with more flexible codebases such as that of Ethereum, they can fully implement the decentralized "smart contracts" first proposed by Nick Szabo (1997) and featuring automatic execution. These contracts not only contain a fixed set of rules that trigger predefined responses corresponding to particular states of the world but also use blockchain's tokens as their enforcement mechanism, so that transactions are supposed to be perfectly enforced in a conclusive or "immutable" manner. Smart contracts therefore realize the "code is law" paradigm coined by Lessig $(1999,2006)$, according to which computer code itself provides conclusive enforcement.

Given this conclusiveness, smart contracts are often considered a fundamental innovation in the way economic transactions can be organized. According to this view, they would make obsolete many of the intermediaries and arrangements that now overcome the lack of trust between traders, including lawyers and judges.

Smart contracts are coded ex ante, at the time of commitment, and, in principle, exclusively by the intervention of (usually one of) their own parties. This may be enough for extremely simple transactions. However, once we move away from such simple trades, smart contracts are subject to the standard limitations that parties to contracts suffer to complete them ex ante and without relying on third parties. (I mean by contract "completion" the task of defining the content of the exchange- that is parties' mutual obligations. In principle, it is safe to assume that, ex ante, rational parties are generally inclined to complete their contracts using efficient terms.)

To be sure, writing contractual terms in computer code instead of legal language does open new opportunities such as greater precision (e.g., Surden, 2012). However, it also poses new challenges, mainly the likely presence of coding errors as well as greater rigidity. More fundamentally, it does not avoid a main difficulty for completing contracts ex ante: the cost of information on the infinite number of possible contingencies.

To solve this informational problem, parties often rely on relational contracts (Williamson 1985), in which a variety of decisional mechanisms, from asymmetric allocation of rights between trading partners to boards of parties' representatives, are used to complete the contract ex post, once uncertainty disappears and parties discover the relevant circumstances in which the exchange will take place. However, completing the contract ex post poses serious problems of partiality and bargaining when ex post decision rights are allocated to one or all of the parties. For this reason, contracts often 
rely on third parties, mainly judges, to complete the contract ex post and enforce the terms of trade, often at the price of sacrificing informational advantages. ${ }^{1}$

In principle, blockchain promised to make little use of specialized third parties for enforcement. ${ }^{2}$ In particular, smart contracts were supposed to work without third-party intervention, avoiding the risk of ledger manipulation by governments or other third parties. ${ }^{3}$ Instead, they must include automatic codified mechanisms for ex post completion and enforcement. This works for simple transactions such as escrow services (Gans 2019), often relying on innovative third party intermediaries. ${ }^{4}$ However, it faces serious limitations for more complex transactions. The most obvious solution, that of establishing ex ante automatic rules for ex post completion, confronts the cognitive limitations of foreseeing infinite contingencies and rightly coding the responses to all of them.

Implementing incentive structures may also help. For instance, Gans discusses how a simple commitment mechanism based on Moore's (1992) "simple sequential mechanism" could replace court adjudication, taking care of several enforcement risks in the trade of goods (seller's low quality and buyer's lack of payment). With blockchain immutability, it would provide parties' bonding with the commitment needed to ensure self-enforcement. ${ }^{5}$ However, it is unclear to what extent the failure of

1 The situation implicit in the previous discussion is one of bilateral trade, which is closer to that of blockchain applications when dealing with users. In addition, contractual problems in blockchain networks often involve many diverse parties (e.g., miners, core and DApp developers, common and master nodes, application users, investors, etc.) with potentially diverging interests and asymmetric and limited information. Such situations are characterized by the presence of multiple potential equilibriums.

2 In blockchain protocols, the distinction between two governance layers (e.g., Buterin, 2017) can be seen as corresponding to the separation between enforcement and completion. Freedom of individual nodes to run any software of their choice produces the bottom "enforcement" layer while coordinating institutions influencing the bottom layer play a "completion" function.

3 To this extent, smart contracts could, therefore, be understood as a paradigm of pure private ordering (Tapscott and Tapscott, 2016, pp. 199-201; Narayanan et al., 2016, p. 285). However, even this effect or at least its importance is uncertain. Not only can states often defeat on-chain blockchain adjudication with off-chain measures but blockchain is in fact triggering substantial demand for court adjudication (Ortolani, forthcoming).

${ }^{4}$ For instance, blockchain applications usually require "oracles" to monitor off-blockchain information for conditions that trigger contractual execution (e.g., whether the market price of oil reaches a certain level when that level is specified in a conditional clause of the contract). Some smart contracts also require competitive arbitration implemented through "2-out-of-3 multisignature transactions" (Narayanan et al., 2016, 278-79), a form of relatively conventional and primitive third-party enforcement (Ortolani, 2016). Moreover, the development of applications and, in particular, smart contracts is increasingly relying on modules created and vetted by specialists. The supply side of the industry is increasingly based on a chain of multiple vertically-linked suppliers, as independent third parties seem to have an advantage in certifying and programming automatic contracts (Casey and Niblett, 2017).

5 Similarly, Holden and Malani (2018) also try to solve the holdup problem using a commitment mechanism implemented through blockchain and based on penalty clauses resembling poison pills. However, courts could always set damages as an increasing function of 
this type of mechanism to become widespread in the past was due to parties lacking the commitment that blockchain is expected to add or, more plausibly, to some other reason which remains unaltered by the emergence of blockchain.

Moreover, the type of adjudication produced would tend to be limited to enforcing the terms of trade that parties agreed upon ex ante, without much ex post completion. Indeed, ex post contractual completion is not only a matter of enforcing well-defined terms of trade but also of defining their optimal content in the given state of nature, filling the gaps in the contract. This ex post completion ideally requires verifying the state of the world which has occurred, and applying a counterfactual hypothesis to guess what the parties would have explicitly contracted if they had considered that state ex ante. Assuming rational agents, this means finding and adjudicating the efficient terms of trade for that particular state (Posner, 1973; Cooter et al. 1979). Such type of completion requires judgment and, therefore, human intervention at least until artificial intelligence becomes much more effective. For now, artificial intelligence seems unable to provide the "self-driving contracts" that would "fill their own gaps and interpret their own standards," as envisioned by Casey and Niblett (2017), whose examples (selfpricing in insurance, short-term rentals and ridesharing) fall short of fulfilling such abilities. In particular, they seem unable to provide the degree of judgment often used by humans to fill the contractual gaps (Abramowicz, 2016), as illustrated by The DAO case discussed next.

\section{B. The Limits of Smart Contracts: The DAO Case}

The DAO was the acronym of "Decentralized Autonomous Organization," a sort of venture capital fund structured as a smart contract in the Ethereum platform. Any investor could contribute "ether," the Ethereum's cryptocurrency, to the fund, thus purchasing shares ("tokens") and voting rights, which they were supposed to use to choose which projects to support. ${ }^{6}$ For a while after its launch it was a successful paradigm of smart contracts, implementing the code-is-law principle. Then, all of a sudden, in June 2016, after it had raised up to $\$ 250$ million from thousands of backers, it emerged that someone had used a bug in its code to "siphon" from its original owners about $\$ 60$ million worth of ether.

This triggered events questioning the fundamentals of smart contracts and blockchain. First, after using similar tactics to fight a so-called DAO war for weeks, the Ethereum team decided to implement a "hard fork." This consists of modifying the software so that it will validate blocks that the previous version considered invalid. It can pursue different goals, from eliminating security hazards in the code to implementing new functions or, as in this case, reversing transactions. If the changes proposed by the Ethereum team were adopted by the community of users, by simply upgrading the software, this would effectively delete the allegedly fraudulent

blockchain damages, so that, at the limit, parties' blockchain assets would be exhausted and the mechanism would become ineffective.

${ }^{6}$ Arruñada (2018) provides further analysis, examples and sources on the concepts and events described in this section. 
transactions and refund the money to its previous owners, but would endanger the conclusiveness of the contracting process.

The hard fork therefore denied the conclusiveness or immutability that was predicated of smart contracts, which were supposed to have the law enshrined in the code, making enforcement and dispute resolution unnecessary. The promoters' power to manage the system also made visible the presence of some degree of centralization. Moreover, their ability to change the rules hinted that the possibility of similar interventions was present in all other blockchain applications.

This cause considerable division within the community, which split after some important miners and exchanges started backing an alternative currency, called "Ethereum Classic" (ETC), which uses the original blockchain. Those who held Ether on it retained their rights, except for the funds stolen in the DAO attack. In the end, "that group of miners continued to mine the original (pre-fork) chain, essentially creating a new coin dubbed Ethereum Classic. By continuing on the non-forked chain, they . . . created two worlds: one where the DAO, along with all the consequences of its hack, still existed, and one where it never happened." (DeMartino, 2016)

This dual reality is possible because, while the only right that users of a conventional centralized currency have is to stop using it, users of a cryptocurrency have another option: they can also fork the rules, meaning that they "would rather operate under a different rule set, and ... go in a different direction from the lead developers.” (Narayanan et al., 2016, p. 171). At the fork, owners of an original coin receive two of the new coins, whose value is determined in the market (here composed not only of investors but also of exchanges and miners) and start operating with their own rules as separate currencies.

The evolution of both coins in the market, in terms mainly of price and volume, hints that both perspectives and the two sets of rules they proposed were valuable. For instance, Ethereum Classic immediately became the third most traded cryptocurrency behind Bitcoin and the hard fork version of ether. Years later, it looked relatively strong, a remarkable achievement considering that it had suffered numerous attacks and even attempts to capture the network. The survival of the two coins plus the fact that their total value was soon greater than the pre-forked value also suggest that the diversity of rules (with immutability in Ethereum Classic but more efficient breach in Ethereum) and, perhaps, the availability of such a competitive process for setting rules are valuable, probably providing better adaptation, as well as better control of the lead developers.

However, even if the goal of Ethereum Classic was to preserve the immutability of the blockchain and the conclusiveness of transactions, its claims of code-is-law were diluted when recognizing that "the infrastructure is not there to enforce and uphold law, it's only a protocol that allows execution of immutable transactions and programs." (Sehra, 2016). Despite being presented as a decentralized, non-governed blockchain system, even Ethereum Classic also relied on third-party enforcement, only in the more conventional form of government intervention. As argued by one of its lead developers, the solution for failures should be based on "Legal Recourse. If anything goes wrong the infrastructure cannot be controlled into changing its state, recourse for financial crime and other illegal activities needs to take place through normal channels.” (Sehra, 2016). It can be concluded that, at least for fraud cases, Ethereum Classic relies on standard legal recourse and blockchain integrity is dissociated from self-enforcement. 
Ethereum Classic was a paradigm, but it is not a unique case. Bitcoin itself suffered a similar experience in the summer of 2017, when trying to reach a consensus to solve the technical, economic, and ideological conflict between miners, who wanted bigger block sizes, and code developers, who stressed security. There was substantial uncertainty, which initially harmed the coin price and seemingly also gave rise to the creation of another coin (named "Bitcoin Cash") through a hard fork. The episode showed again how the deficit in formal governance structures was decided by a hard fork, disciplining lead developers in the same way as the DAO incident suffered by Ethereum one year earlier. Since August 2018, Bitcoin has split 18 times, according to Biais et al. (2019).

\section{Conclusions on Contract Rights}

The failure of The DAO showed that implementing the code-is-law principle is harder than it seems, as a failure in the drafting of the original contract led to its subsequent revision, showing that its terms were not conclusive and the blockchain was not immutable. Blockchain is always open to ex post completion, at least in the form of a hard fork: whatever the intent of those promoting Ethereum Classic, even the community behind this purist blockchain could at some point implement a hard fork to reverse transactions. Even in the blockchain universe, code is law but not all the law is code.

More generally, The DAO fiasco showed that a presumed advantage of smart contracts - automatic enforcement - becomes a liability when it is efficient not to enforce the contract. In other words, automatic execution is detrimental to the extent that it precludes contractual breach, which is optimal in many uncontractible circumstances (Cooter and Ulen, 2016, p. 328; Shavell, 2004, pp. 304-14). This possibility therefore requires ex post decision mechanisms to achieve efficient trade.

These lessons hold some important consequences for blockchain initiatives in terms of which industries and types of contracts may benefit most from implementing them.

First, the presence of uncertainty emphasizes the need for adapting and completing the contract ex post, once more information is known about the relevant state of the world. Not only implementing smart contracts often requires new forms of ex post completion and third-party enforcement, based on new types of intermediaries, such as those mentioned in note 4 . The DAO and similar cases show that blockchain systems may depart from the pure code-is-law paradigm by denying enforcement through hard forks. Understandably, many blockchain ventures are trying to reduce the risk of network splits caused by hard forks, by devising innovative governance mechanisms which facilitate formal and explicit ex post completion. ${ }^{7}$ For instance, the EOS blockchain, relying on elected master-nodes, provides arbitration and judicial services designed to complete contracts, even enforcing subjective terms, as well as fixing code bugs, freezing misbehaving accounts and allowing users to designate key-recovery partners (Larimer, 2018).

7 Arruñada, Espinosa and Garicano (2018) discuss the mechanisms designed by Dash, EOS, Tezos and Dfinity, which are based on different varieties of coin-holder voting. 
Second, as in other attempts to enable impersonal exchange, it makes sense to argue in favor of contract simplicity. For instance, a root of the DAO problem was that smart contracts also face the traditional tradeoff between security and complexity (Shea 2016). Errors in computer code are prevalent and impossible to eradicate, and they increase with complexity, as with conventional contracts.

Two practical consequences emerge from the limitations of ex ante completion and the prominent role of simplicity. On the one hand, they help to explain why blockchains - like computable contracts early on (Surden, 2012) — have been gaining more ground in the financial world and, in particular, in areas such as payments and derivatives trading (ISDA, 2016, p. 23): note that they are highly standardized, so that parties are able to contract legal commodities.

On the other hand, for low-value transactions, complex contracts are too costly to write and enforce, and low-value assets are not valuable enough to define multiple rights on them. To the extent that contractual and property simplicity are therefore negatively correlated to the value of transactions, blockchain and smart contracts also develop more easily in low-value contexts.

Third, blockchain clearly adds value by providing verifiability on the content of contractual documents (Catalini and Gans, 2016), with obvious competitive consequences for authentication services such as those provided by notaries. However, it is less clear to what extent or in which cases blockchain is able to make contractual performance verifiable. In particular, while blockchain likely makes contractual performance easier for parties to the contract to observe, it does not necessarily make it easier for third parties, including judges (Gans, 2019), to verify performance.

To the extent that blockchain provides parties' observability but does not enhance third-party verifiability, it should favor second-party over third-party enforcement. It should therefore favor "relational contracting," understood as the type of exchange that is safeguarded by parties' reputation and expected gains from trade (Klein and Leffler, 1981; Shapiro, 1983; Levin, 2003). This should affect the ability of parties not only to self-enforce the contractual terms without the intervention of third parties but also to complete the contract ex post, filling the gaps and adapting it to unforeseen contingencies (i.e., "relational” à la Williamson, 1985).

Moreover, applications enabling business-to-business (B2B) transactions could rely on "private" and/or "permissioned" systems, which are open for trade only to preapproved users and/or in which the consensus may be driven by a previously established set of nodes. In this vein, private blockchains should expand rapidly in supply chain management, revamping the existing and mostly closely-knit networks of suppliers, manufacturers, and distributors, which are already characterized by phenomena such as “contract manufacturing,” (Arruñada and Vázquez, 2006) as well as "virtual integration" (Arruñada, 2002b). Financial institutions are pioneers in this regard.

However, permissioned blockchains will face a basic contradiction: the smaller the network, the smaller the extent and the fewer the advantages of decentralization, and the easier it may be to manipulate it (Narayanan, 2016, pp. 34-38). They may therefore end up featuring little decentralization, causing little disruption, and even entailing some risk of collusion among incumbents.

In addition, the use of blockchain for tracking the flow of goods and services in supply chains could affect informal relational contracts which, on purpose, are not formalized in order to ensure self-enforcement and preclude third-party adjudication 
(Hadfield and Bozovic, 2016). In settings of repeated transactions (such as the typical interaction between consumer-goods manufacturers and large retailers), the blockchain would provide an immutable record of parties' actions, which courts could then use to ascertain the existence and content of the informal contract. In particular, disgruntled parties could now argue before the court that their counterparties have performed below the agreed terms, terms which they could ask the court to infer from their previous level of performance, now verifiable in the blockchain record.

Lastly, the comparative advantage of blockchain applications would be considerably enhanced if the technology fulfills its promise of enabling individual users to own and keep full control of their historical record of transactional data, which is now in the hands of third-party centralized data silos (such as Google, Facebook or Booking). Availability and ownership of transactional data would make it possible for individuals to, first, accumulate reputational capital; and, then, deploy such capital to safeguard their transactions across multiple markets and using different platforms and applications. Such a system would benefit from massive economies of scale and scope, and could achieve secure personal transactions with anonymous parties, therefore providing an effective alternative to impersonal (i.e., asset-based) exchange. This mobilization of reputational capital could eventually become even more valuable and transformative than the mobilization of land as collateral for credit (De Soto et al., 1986). Difficulties are numerous, however. For instance, reaching such economies without substantial centralization, and making the necessary investments without any possibility of capturing value in the future.

\section{Blockchain AND Property, In ReM, Rights}

\section{A. The Need for a Public Interface Between Personal and Real Rights}

A public ledger currency platform is "a protocol for sending, receiving, and recording value securely using cryptographic methods” (Evans, 2014). In addition to exchanging value, to what extent are these systems capable of exchanging property? Exaggerated but conveniently imprecise claims are common-for instance, it is said that "[u]npermissioned ledgers can be used as a global record that cannot be edited: for declaring a last will and testament, for example, or assigning property ownership" (Taylor, 2016, p. 17, emphasis added).

These claims are valid for cryptocoins but note that these are very special assets: they exist only in blockchain and, more deeply, being a sort of bearer instrument-they work like cash-, their possession equates ownership. However, with the exception of assets for which possession is in fact the only property right, such as cryptocoins and cash, contracting property requires at least one intermediary (a registry or a court) between the world of mere claims (i.e., in personam rights) and the real world of in rem 
rights. ${ }^{8}$ Blockchain applications in which parties trade claims on assets existing outside the blockchain ledger require interfaces between the digital and the real worlds.

At a minimum, these interfaces make it possible for claimants to get physical possession of the assets. But the key issue is to what extent they perform a legal transformation, a sort of second "public contract," through which mere claims against specific individuals are upgraded into property rights valid against the whole world (Arruñada, 2003). In this, they resemble the conventional legal institutions between contractual (in personam) and property (in rem) rights. ${ }^{9}$

The presence of such a legal interface is not new. In land law, two or more contradictory chains of title deeds often coexist. But upgrading one of the claims to a right in rem requires a third-party enforcer-a court and/or a register, or, in primitive legal systems, a communal decision - in any case, an independent adjudicator safeguarding the interests of all potential rightholders, including those outside the chains of title. Note that, in a sense, a chain of paper title deeds is also "virtual," as it is based on documentary possession and reflects mere claims; therefore, if parties to the contract agree, it can also support trade in claims without necessarily having in rem consequences for the traded assets.

This account is consistent with a salient feature in analyses of blockchain applications in "smart property" that use examples in which they are in fact describing transfers of possession instead of transfers of ownership. Note, for instance, how the running example of a "car whose ownership is controlled through a block chain," used in chapter eleven of Narayanan et al. (2016, p. 272, emphasis added), immediately turns out to be a transfer of possession:

The block chain transaction doesn't merely represent a change in ownership of the car: it additionally transfers actual physical control or possession of the car. When a car is transferred this way the earlier owner's key fob stops working and the new owner's key fob gains the ability to open the locks and start the engine. Equating ownership with possession in this way has profound implications. (Narayanan et al., 2016, p. 274).

The implications are indeed profound but they are achieved by degrading ownership into less than possession - that is, by enforcing at most only a single right in the asset. ${ }^{10}$ The price being paid is huge because the modern economy is based on the specialization (or, some would say, separation) of ownership and control (that is, in its simplest sense, possession). If blockchain's smart property is limited to possessory rights, the word "merely" in the preceding quotation should be excised and the word “additionally” replaced by “only”. In practical terms, this limits stand-alone (no trusted third parties) applications of smart property to bearer instruments and low-value assets,

8 On rights in rem, see Merrill and Smith (2000), and Hansmann and Kraakman (2002).

9 Abadi and Brunnermeier (2018) make a somehow similar point, by distinguishing between mere "record-keeping" — which could be better seen as in personam claims — and "enforcement" — of, in my terms, in rem rights—, also misattributing the concepts of ownership and possession.

10 In fact, less than possession because having an active key fob does not give you physical possession or control of the actual car but merely the ability to exercise that control... if you actually have physical possession of the car. I thank Rod Thomas for this insight, which, as we will see, also has serious consequences for real estate. 
as Narayanan et al. themselves seem to conclude a few pages later (Narayanan et al., 2016, p. 284).

These are serious concerns for the common claim that all types of asset can be transferred in the blockchain. The legal effects of such transfers, at least, would be limited to the transferring parties. Indeed, property rights are in the sphere of public ordering, and pure "privacy” is only viable when parties trade in contractual claims. It therefore comes as no surprise that such concerns are also echoed in the caveats often introduced when foreseeing blockchain applications. For example, a prominent entrepreneur claimed that "Bitcoin gives us, for the first time, a way for one Internet user to transfer a unique piece of digital property to another Internet user" (Andreessen, 2014). Note, however, the "digital" adjective: one cannot send real property over the Internet or, more precisely, one cannot even transfer possession of real property over the Internet. ${ }^{11}$

For the same reason, it is understandable that enforcement of peer-to-peer decision systems is easier when they deal with digital resources being held in escrow. Not only is the losing party less effective in preventing enforcement but courts are unlikely to interfere because usually there are no claims by third parties. Even Nick Szabo, when implementing his idea of property clubs, also seems to be contemplating rights in personam: "Actually getting end users to respect the property rights agreed upon by this system will be dependent on the specific nature of the property, and is beyond the scope of the current inquiry” (Szabo, 1998-2005).

The problem of relying on personal rights is that they offer weaker enforcement, reducing welfare (Arruñada, 2012, pp. 18-24). Understandably, for most durable and valuable assets, parties demand multiple in rem rights. And meeting this demand requires the intervention of a third party with a necessarily public function, as it must be impartial to all and prevail over the parties to any given contract (Arruñada, 2017). Such a third party is necessary at least to define the set of rights enforced in rem (often referred as the numerus clausus of rights) and the mechanisms and evidentiary requirements for rightholders to convey their consent with respect to intended transactions.

\section{B. Blockchain-enabled Peer-to-Peer in Property}

In theory, if this gathering of the relevant consents were complete, blockchain could even sustain peer-to-peer (i.e., person-to-person, P2P) exchange and titling of property rights without relying on any private or public intermediary (assuming the blockchain platform is running and properly maintained), the option depicted in the first branch of the decision tree represented in Figure 1.

11 A somehow similar caveat is introduced by Abramowicz when he considers the limitations of bitcoin, also given a limited meaning to property rights: "Bitcoin can be seen not just as a currency, but more grandly as an institution that creates and enforces property rights. It is an institution, however, that can resolve only one type of decision: whether purported transfers of Bitcoins will be validated and added to a list of approved transfers, known as the block chain.” (Abramowicz, 2016, p. 361). 
In theory, such a peer-to-peer trading platform could even be capable of enforcing indefeasible title, as well-functioning registries of rights do. The reason is that even if it is their registrars who custody rights and gather rightholders' consents, it is individual rightholders who decide when granting or denying their consents. In principle, it is conceivable that these custody and gathering tasks could be governed by an automated system, including a decentralized one based on blockchain.

This would require several feats, however.

At the individual level, a truly peer-to-peer system for property exchange and titling would require the ability and willingness of individual rightholders to make their own decisions with respect to property rights, bearing the risks of such decisions. In a hypothetical, fully-decentralized property system, all individuals would therefore be granting or denying their consent to intended transactions affecting their property rights. Consequently, they would become the only custodians not only of their cryptographic keys (to receive notice and grant consent) but also of the legal integrity of their rights. In particular, with a pure peer-to-peer system, security of ownership (generally, of any right) would be limited to keeping the private cryptographic keys in the possession of the owner (generally, in the possession of the corresponding rightholder).

In addition, at the public level, blockchain registers would pose similar difficulties to those often faced when reforming property titling, such as, for example, when countries: (1) replace customary titling with a register-based system and have to ensure a smooth transition between both systems; (2) have several registries working in parallel and have to ensure that the law reduces the risks created by switching; or simply (3) want to reinforce the effects of a register with respect to overriding and possessory interests. In all these cases, if the law wants the new system to be effective, it must prevent individuals from abusing the exercise of choice of titling to the extent that titling kills preexisting property, in rem, rights. Legal cautions are most obvious in jurisdictions such as Massachusetts, which, having multiple land registers, tightly regulate switching (Arruñada, 2003:428-32), but are also present in other cases in which there are strict requirements for first registration and deregistration.

Implementing a blockchain register would face similar difficulties-e.g., adverse selection — and would have to meet similar demands—strict legal requirements for first registration, deregistration and switching registers- . It would also pose some specific additional problems. First, rightholders would be choosing not to be protected by registries and courts. This would probably require some safeguards to ensure that individuals are informed about possible consequences. Second, at least in theory, several blockchains could function in parallel, so that owners could choose in which one to register their property. In that case, any issues arising from blockchain ledger interoperability would have to be resolved to prevent the same asset from being registered in two blockchains (Cuomo, 2019).

Minimum necessary regulation would include: (1) defining the legal status of blockchain records to establish priority of claims and adjudicate property rights among conflicting claimants; (2) establishing a low and strict numerus clausus-exclusive of all unregistered rights - before coding a smart contract capable of handling property conveyancing and/or registration; (3) regulating the switch of title records or property rights to the blockchain register, a task which differs widely if mandatory or voluntary; if voluntary (as is likely inevitable in most cases), regulating any conflicts emerging from the resulting multiple sources of legal evidence, possible parallel sources of evidence and even overlapping registries; and (4) regulating the legal status of non- 
contractual property rights such as those derived from, e.g., judicial seizures, inheritance rights or even constraints rooted in land planning.

In practice, however, a peer-to-peer property system could not be universal and would instead rely on intermediaries for the majority of individuals. Decentralization is limited in the real world because individuals tend to misbehave with respect to security: "We were able to achieve decentralization only because we equated possession with ownership —owning [an asset] is essentially equivalent to knowing the private key corresponding to a designated transaction on a block chain” (Narayanan, 2016, p. 283). However, reducing ownership to securing the possession of private keys poses serious risks for nontechnical users, and any remedies lead us back to intermediaries.

Misbehavior with respect to security is only an instance of a broader and deeper phenomenon: individual freedom has a price in terms of individual responsibility that not all individuals are always willing to pay. Instead, knowing their own weaknesses, they often prefer to rely on centralized solutions based on private and public custodian agents who are motivated by making them liable for all sorts of failures, including security breaches. Such solutions include the strict liability of some registrars, indemnity funds in Torrens systems, and US title insurance).

This theoretical judgment is supported by empirical evidence from current blockchain systems. The fact is that most individual agents who are today trading bitcoin and other cryptocoins rely at least on intermediaries such as exchanges (digital marketplaces) and wallets (digital storage services) and, therefore, a fortiori, are even less likely to rely on peer-to-peer exchange without intermediation to trade their real property. Similarly, rightholders who to date have been shunning cryptocurrencies would be even less willing. This reluctance is present in all types of applications, but, understandably, it especially constrains those in which the stakes are higher, leading people to demand greater security.

In practical terms, blockchain applications in property are likely to demand that public authorities regulate the interaction between the two parts of a dual titling system (e.g., with intermediaries for most individuals and, at most, peer-to-peer systems limited to specialists such as traders in the secondary mortgage market), as well as regulating such intermediaries themselves.

This regulation is affected, in particular, by the possibility of hard forks, which makes reliance on public unpermissioned blockchains unsuitable for property rights and requires the system to be based on private permissioned blockchains. ${ }^{12}$ (Note that a government-controlled blockchain is still "private” with respect to blockchain validation). States with weak bureaucracies may be happy to use unpermissioned blockchains to enhance the integrity of their title records (to some extent, this is the case of Georgia, to be discussed below). However, whatever the reliability of their bureaucracies, states will be unlikely to surrender their role as ultimate property adjudicator, which is what they would be doing with unpermissioned blockchain

\footnotetext{
12 See, for instance, the arguments in this regard of the Vermont Secretary of State: "It's unclear how a fork would affect the long-term reliance on blockchains as systems of record. Since there is not necessarily any long-term commitment to participation in any blockchain network, a fragmentation of a blockchain could pose a significant challenge: when verifying a record's authenticity in one of the above models, users would have to know which of the various different forks of any one blockchain are authoritative” (2019, p. 24).
} 
registers. Moreover, weak states are most unlikely to be able to credibly commit themselves in this direction.

\section{Blockchain-enabled Intermediation in Property}

The second branch of Figure 1 represents the different types of possibilities for intermediary-based systems, with more or less presence of blockchain in the two stages of the property contractual process (Arruñada 2003): private conveyancing and public titling. In principle, blockchain could be implemented in either one or both of the two stages. These possibilities include (1) introducing blockchain to support conveyancing and/or registration, (2) relying on conventional conveyancers as intermediaries between individuals and blockchain-enabled systems, (3) enhancing conventional registries to act as blockchain-enabled conveyancers, and (4) keeping registration review in the hands of humans or making it more automatic.

\section{PLEASE INSERT FIGURE 1 APPROX. HERE}

In principle, some of these possibilities are more realistic than others, mainly because of technical hurdles and the presence of strong vested interests. Moreover, some of them are more applicable to specific property rights and specific rightholders. For instance, due to individuals' bounded rationality, blockchain could more easily support a secondary mortgage market with few professional participants interacting through a permissioned peer-to-peer system than a primary market in real estate with individuals free to trade as sellers, buyers and borrowers. ${ }^{13}$

Moreover, some of these solutions can only be implemented through particular types of blockchain developments, which, in turn, would often require specific legal interventions. Understandably, the more ambitious the application, the more demanding it is in terms of technical constraints and the legal changes required. The least demanding option is that of posting digital identifiers often known as fingerprints and "hashes" of title deeds in an unpermissioned blockchain to enhance record integrity. However, registering actual title records in a blockchain requires a permissioned blockchain to make it viable in terms of mining (validation) costs; a blockchain system of conveyancing or registration based on tokenized titles requires transforming property titles into negotiable instruments; and a blockchain register based on a smart contract would also require a strict, low numerus clausus of rights to make such a contract writable.

The next section analyzes this second branch of Figure 1, focusing on pilot and real initiatives to discuss the possible application of blockchain in the areas of property conveyancing and deed recordation, as well as company and property registration. ${ }^{14}$ In

\footnotetext{
13 Note, however, that missing the private keys is more irreversible for mortgages and other abstract property rights, as they lack possessory evidence which could be used to restore the right.

14 See Allessie et al. (2019) and Antelo (2019, ch. 3) for more detailed descriptions and analyses of some of these cases.
} 
general, the analysis focuses on the difficulties of automation, whatever the technical solution being implemented, In fact, some of these possibilities do not require blockchain, and those which are based on blockchain often end up with a significant degree of centralization, further questioning the blockchain philosophy.

\section{Blockchain in Conveyancing and Registering}

The impact of the blockchain on conveyancing and property titling is affected by the basic characteristics of both legal processes, which, in line with the incentives of participants, are mostly private in conveyancing and intrinsically public in registration. In particular, both processes are defined by the fact that in all property systems parties are free to choose their lawyers, conveyancers, and notaries public (Arruñada, 2003, pp. 424-28). Conversely, third-party protection leads the law to universally restrict parties' choice of the office that records their titles or the registrar that preserves and reviews their rights, as well as the judge who presides over a suit of quiet title or any equivalent judicial procedure. Therefore, blockchain should find it easier to expand into notarization and data archiving. It will be more difficult for blockchain to replace the current functions of centralized land registries, especially in jurisdictions such as Australia, England, Germany and Spain that have registers of rights, also often called “land registration” or "title by registration” systems (Arruñada, 2003, pp. 406-23). Replacing them would require at least a low numerus clausus and substantially greater investments in artificial intelligence.

To the extent that even in civil law jurisdictions notaries public are freely chosen by parties to private contracts, the blockchain will likely play a bigger role in notarization, even in real estate transactions. The only functions for which notaries used to be superior were for identifying parties and, in civil law countries, for ascertaining their legal capacity and serving as providers of settlement, closing, and escrow services for parties (Arruñada, 2007b). These advantages, which have been under threat for decades from complementary technological developments in identification and the related availability of registries for individuals' legal capacities, are now substantially affected by blockchain, which has allowed the development of services that prove to other parties that you are who you say (authentication) and that you have the required permissions (authorization). Likewise, with respect to settlement, trade implemented through a blockchain can now provide conditioned simultaneous enforcement by using the principle of "atomicity," which, in essence, ensures that both parties fulfill their promises at the same time (Narayanan, 2016, p. 274).

Conversely, the applicability to registries of a truly decentralized blockchain (i.e., without trusted intermediaries) will likely require a greater effort than in notarization because registries have a public legal function, that of protecting the interests of unrepresented third parties, and are therefore much more than mere public databases. Centralization and monopoly in registries are not rooted mainly in economies of scale but in the need to enhance the neutrality (with respect not only to parties to the contract but also to strangers to it) required to reach universal legal effects.

However, blockchain enthusiasts often follow the path of efforts in property titling and administrative simplification, paying scant attention to the legal function of 
registers. This bias is visible in the diagnoses of existing systems by blockchain entrepreneurs trying to test the technology in the area of property titling, whose policy failures they seem to attribute to incomplete and slow data management, with an engineering perspective that makes no reference to the register's incentives (Kempe, 2017, p. 15). However, in reality, the harder task of property registries is not archiving information, but producing reliable information. It is not a problem of keeping a record of perfectly "purged" (i.e., non-contradictory) property rights, but purging them and making sure that intended transactions do not collide with preexisting property rights. The tasks of "collecting and recording the data" (Da Costa et al., 2019, p. 323) are necessary but are not the key element of property systems, for which multiple rights on an asset must be enforced in rem. Despite the fact that purging rights is mainly a legal issue, not a technological one, attempts to apply blockchain in property registration often focus instead on archiving and on keeping the integrity of the information (e.g., Goldman Sachs, 2016), disregarding how the information is produced and, especially, the whole process of how property rights are purged of contradictions.

Consequently, if this purging is something for which blockchain is perhaps of little use, grand claims on the potential of the technology in this area should be substantially diluted. This helps to explain why pilot projects often stall. It also explains why analysts focusing on data management fail when pondering the effects of blockchain on Torrens registers' indemnity levels (Graglia and Mellon, 2018, 105-106) and US title insurance premiums (Goldman Sachs, 2016), which they seemingly contemplate as independent of the title purging function performed, respectively, by registrars and lawyers (Arruñada, 2002a). Moreover, the question as to how much security is in fact provided by blockchain is an empirical one.

On the positive side, however, blockchain may lower the costs of identifying rights and assets, making new types of registers viable, and enabling finely-tuned solutions for more detailed rights in intellectual property as well as completely new registries for certain high-value assets, as suggested by the Everledger initiative for registering diamonds and other specially valuable assets (Lomas, 2015). Note in this regard that private ordering arrangements enjoy an advantage when rights are unenforceable in rem, as with assets that are "easily portable, universally valuable and virtually untraceable," such as diamonds, which explains why the diamond industry has been based on a "millennia-old distribution system that relied on multiple layers of personal exchange" (Richman, 2009). Blockchain would alter this advantage if it is capable of relaxing this constraint, so that it becomes economically viable to identify each individual asset, this being one of the stated objectives of the Everledger registry.

\section{E. Blockchain in Recordation of Deeds}

It is conceivable that a deed recordation system might be replaceable by an automatic system of dating private contracts and preserving their integrity. In this case, new laws should be enacted to modify the rules of evidence- that is, to set the priority of the blockchain as a source of evidence for in rem adjudication, which in US law would require granting exclusive powers to produce constructive notice to the blockchain. This is because, for a blockchain to produce in rem effects, all parties must be explicitly or implicitly (through priority rules) obliged to express their will through 
it. Moreover, the priority of blockchain must not only be legally established but also effective. This means that, as with any other source of evidence, judges must in fact trust the blockchain and, therefore, those designing, putting in place, and-to some extent-governing, or at least affecting, the government of the blockchain system. Otherwise, whatever the legally defined priorities, the conventional conflict between alternative sources of evidence would likely arise (Rose, 1988), with judges using any available excuse (often based on implied notice or lack of good faith) to overcome the formal priorities set by statutory law.

Let us take these three dimensions (i.e., register replaceability, priority rules and judicial trust) to examine the first main—if modest—attempts to apply blockchain within recordation systems.

First, while the firm developing the pilot project carried out in Cook County (Chicago, Illinois) seemed optimistic (Lifthrasir, 2017), the official report concluded that relying on an unpermissioned peer-to-peer system would be too costly in terms of energy and would force most owners to rely on third parties. It therefore favored permissioned systems, limiting the use of blockchain to conveyancing and lodging while retaining the existing legal framework according to which "the county government record is the only official record” (Yarbrough, 2017, p. 22). No replacement is in sight and, in the pilot, priority was planned to be established by filing a deed at the public record office. (Apparently, finally it was never recorded). The plan was for the blockchain transaction to be notarized in a conventional "confirmation deed" (a type of deed mostly used to correct mistakes). In a similarly minimalistic vein, the report considers that the chosen technique of "tokenizing” title (thus transforming real property into negotiable instruments) would pose substantial new legal challenges, and using digital signatures would facilitate secrecy and endanger the identification of participants.

Second, the pilot carried out in Vermont by Propy, an online real estate listing service specialized in cross-border deals and expanding into conveyancing and closing services, also falls short of replacing the register, which in this case would mean replacing the register's software with that of Propy. A legislative decision modifying the rules of evidence made it possible for a couple of paper deeds produced using Propy's smart-contract, Ethereum-based, blockchain platform to eventually be lodged at the record office of the city of South Burlington. In this respect, the pilot was therefore less limited in scope than that of Cook county. However, the paper deeds lodged at the record office included information (the deed smart contract's address) as to where the transaction is located in Propy's blockchain, therefore providing some degree of crossverification. As with the Cook county pilot, the city's clerk is skeptical even about the complementary use of blockchain, which seems far from Propy's aim of having the statutes changed so that its blockchain would produce constructive notice "regardless of the status of the existing municipal title records" (Voloshyn, 2018). The Secretary of State was also skeptical, arguing that "blockchains do not solve any problems that the State of Vermont and its political subdivisions have.... In fact, more problems might be introduced with having a set of records stored in a blockchain that now, too, must be preserved and have access provided to it.” (Vermont Secretary of State, 2019, pp. 3738). In any case, even if it had been fully developed, the system would not have contemplated peer-to-peer transactions but would have relied on conventional intermediaries intervening via the blockchain-based platform. 
Lastly, the application developed by the land register of Georgia also illustrates the importance of titling institutions being trusted by the courts. The starting point is an unreliable register which was legally defined as a register of rights, but in practice lacked proper registration review and worked as a recorder of deeds competing with the Cadaster in the provision of title evidence to judicial decisions. This explains why in 2017 the Constitutional Court removed the presumption of accuracy that the law granted to registry records. In this context, blockchain was implemented to make the register more trustworthy on the eyes of judges by, first, using a private permissioned blockchain for archiving notarized deeds (i.e., a unified version of the notaries' "protocol") and, second, relying on the public unpermissioned Bitcoin blockchain to publish snapshot hashes of the title certificate, in the hope of enhancing integrity and precluding the manipulation of records.

\section{F. Blockchain in Company Registration}

The case of company registries is similar to that of recordation of deeds, to the extent that most company registries are closer to recordation than to registration systems. However, company registries could also be challenged by initiatives like the Ethereum blockchain, as these allow the creation of virtual decentralized and autonomous organizations that would be defined only by a given set of rules running in the blockchain. In principle, such organizations can be flexibly organized, allocating specialized managerial and contractual functions in different manners (Abramowicz, 2016).

However, a historical perspective throws light on the potential contribution and likely difficulties of this contractual approach to company incorporation. The experience of the English "unincorporated companies" prior to the creation of the English Company Registry in 1844 provides relevant insights (Harris, 2000; Arruñada, 2010a). In general terms, these authors suggest that, even assuming perfect immutability of the blockchain, the explicit backing of the law and judicial rulings seem indispensable for avoiding future conflicts ex post and providing parties with the necessary certainty ex ante.

Understandably, the state of Delaware launched in May 2016 an ambitious "Delaware Blockchain Initiative" in partnership with a software firm, contemplating applications to archiving, secured corporate loan filings and share registration, but it collapsed a few months later, amid a controversy over the real value added and alleged vested interests of registered agents (Baker 2018). It was soon replaced by a more modest strategy, which led to a pilot on special-purpose corporations and to allowing companies to keep their records and handle their stock ledgers on a blockchain. Other states have been active in using blockchain to compete for the corporate franchise business. For instance, a law enacted in the US state of Vermont allows the incorporation of blockchain-based limited liability companies (BBLLCs), making it possible for blockchain platforms to formalize their governance structures instead of being informal partnerships (Tashea, 2019).

In addition to keeping share registers updated and tracking beneficial ownership more effectively, with potentially serious repercussions for corporate governance and financial transparency, blockchain also has important implications in less glamorous 
corporate areas. In particular, it has the potential to automate "corporate actions": any announcements made by a public company affecting its securities and which may require a response from either investors or their representatives. Examples include dividends and coupon payments, offers to issue or redeem securities, stock splits, mergers, and spin offs. Most of this data is now communicated to investors through a complex channel involving suppliers of financial data, securities' custodians, and investment fund managers, who then also carry investors' decisions in the opposite direction. In both directions, blockchain aspires to make the whole process automatic and more efficient (Hobson, 2016).

\section{G. Blockchain in Registration of Rights}

All registers of rights include a record of claims in their lodgment book, which they use to establish priorities before subjecting intended transactions to registration review-i.e., during the registration gap between lodgment and registration, the register of rights acts in fact, for the intended transaction, as a register of deeds. What has already been said about recordation systems therefore applies to the lodgment book of registers of rights.

In comparison with property recordation and company registries, the defining stage of registers of rights is registration review - the essential task to safely upgrade personal claims into real rights - , as keeping a reliable and verifiable register of rights should not be qualitatively different from keeping a reliable record of deeds. Therefore, the specific difficulties are not so much those of combining blockchain with registration review performed by humans, as seemingly suggested by some analysts, ${ }^{15}$ but whether it is possible, and at what cost, to perform such a review automatically.

Applying blockchain to registration review means replacing humans with an automatic system. From a theoretical perspective, this replacement would face similar difficulties to those considered above with respect to contractual completion. From an empirical perspective, it would pose similar challenges to the centralized automatic review which has been operating since 2009 in New Zealand, where solicitors were given the power to modify a Torrens register of indefeasible rights. As analyzed elsewhere (Arruñada, 2010b), the effectiveness of such automatic review is open to question and its sustainability, given current difficulties to collocate economic risks and decision rights (Thomas, Low and Griggs, 2012), is in doubt and has to be judged in the long run.

Blockchain partisans would likely take issue with this analysis arguing that, in a truly peer-to-peer system, no centralized third-party verification is necessary because all

\footnotetext{
15 These theoretical analyses reach negative conclusions on different bases and referring to different registries. For instance, Thomas (2017) argues that a blockchain system based on trading "colored" coins through Bitcoin could not support a Torrens register because it would not allow verification by an independent registrar. Also assuming a Torrens register, Griggs et al. (2017) consider that blockchain would not avoid two of the typical forms of title-related fraud. Gallego (2017) contends that a register of rights based on an unpermissioned blockchain would find it hard to enforce priority and would preclude registrars' review. Moreover, a permissioned blockchain would offer no advantage over conventional technical solutions.
} 
rights would be in the blockchain and rightholders themselves would be granting their consent directly to the automatic system. This is true but both requirements are too tight.

First, when creating modern land registries, the standard historical solution to have most in rem rights registered and to simplify registration review has been to reduce the variety of rights enforceable in rem, defining a smaller and closed number of in rem rights (Merrill and Smith, 2000; Hansmann and Kraakman, 2002). This reduction of property rights is worthwhile to the extent that it makes it possible for registers of rights to function or, in general, reduces information asymmetries in markets (Arruñada, 2003). However, it is also costly because a smaller set of rights benefits from the advantages of being enforced in rem. (Note that the effect is not so much to constrain freedom of contract-parties remain free to contract personal rights-as to limit enforcement possibilities.)

Second, in a fully decentralized system of property, all individuals would take care of their rights by themselves. They would need to keep their cryptographic keys and to decide about any transaction that other individuals propose which might affect their rights. As mentioned previously, many individuals, probably the majority, would prefer to rely, at least partly, on trusted private and institutional intermediaries, including conveyancers, title insurers, banks and registrars.

Proposals to apply blockchain in the registration of real property confirm this analysis as they opt to preserve the review role of registrars. For instance, a Swedish pilot project (Kempe, 2016, 2017) provides a valuable illustration as, in essence, it is limited to reorganizing the in personam contractual process precedent to the in rem property transaction. ${ }^{16}$ The changes proposed thus resemble the system of electronic conveyancing and registration implemented in New Zealand, but with a key difference: the Swedish Land Register (the Lantmäteriet) would retain all its powers to review and decide on registration: "Updates to the land registry are retrieved from the blockchain and are then also checked by Lantmäteriet. Registration in the blockchain is digital and based on the legal requirements, which minimizes errors in the information." (Kempe, 2017, p. 59). The register would also define the assets and, supposedly, the authority to deal (p. 38).

Therefore, the only substantial change is the development of a private permissioned blockchain application for electronic conveyance, which would allow all parties involved to work with the same information, expanding their knowledge and reducing duplications and mistakes (pp. 43-44). A benefit would be that all parties would also gain instant access to any filing in the register that may affect the legal standing of the rights being traded.

On the other hand, the system would work with "pending property titles” during the whole conveyance process until eventual registration, which both the White Paper (Kempe, 2016) and the Testbed (Kempe, 2017) hope would always be granted by their assumption that registration refusals are now mainly caused, not by the complexity and incompleteness of property rights, but by bureaucratic mistakes: "The risk that the property title will not be granted is sharply reduced since the system can ensure that the information that is required by law is included in the system and is required by the system before the parties are able to provide their signatures” (Kempe, 2017, p. 54).

16 The current proposal for the English Land Register (Tombs, 2018) does something similar. 
However, even if most refusals have been rooted in bureaucratic errors, it is likely that the important refusals in terms of value and legal security will be those that impede dubious, borderline or even fraudulent transactions from damaging strangers to the intended transaction. In principle, it is unclear how they would be affected by the new system unless the law reduces the numerus clausus.

If this analysis is correct, two important consequences follow. First, the land register would have to maintain its review functions to avoid the serious risk of transforming a register of rights into a recording of deeds (Arruñada, 2012, pp. 210-12). In fact, the demand for registration review might well increase because the proposed system gets rid of the notaries who, under the current system, verify parties' identities and contractual will. Under the proposal, parties would instead input their decisions directly. At the time of writing, legal noncompliance in this dimension is blocking application of the proposal (Allessie et al. 2019, p. 30). Second, speeding up the whole process and maintaining the same level of legal security likely requires introducing advanced registration review at an earlier stage of the transaction. "Pending" titles would then be upgraded to "conditional” property titles.

\section{CONCLUDING REMARKS}

The paper explores the impact of blockchain on the roles played by existing intermediaries in contract and property transactions. It argues that the core peer-to-peer structure of blockchain faces serious difficulties to reach contractual completion and to interact with the real world. These two difficulties have been analyzed here from the perspective of, respectively, contract (in personam) rights and property (in rem) rights.

Except for extremely simple or low-value transactions, pure code-is-law mechanisms are insufficient. Therefore, blockchain networks and applications will devise governance structures and demand specialized services to provide effective contractual completion, as well as interfaces between the virtual and real worlds. Governance mechanisms are necessary at different levels in order to complete both network protocols and application contracts ex post, but pose a risk of centralization. Specialized services reduce some costs (e.g., contract writing) at the price of increasing agency costs, therefore creating additional conflicts of interests. Both forces will likely trigger greater demand for regulation and third-party enforcement.

Blockchain faces an even harder struggle to move from the world of personal rights to the world of real (i.e., in rem) rights. This leap will require public interfaces and interventions - mainly, to clearly establish and enforce the status of the blockchain as judicial evidence. Moreover, all other factors being equal, applications of blockchain in the field of property transactions are easier in document notarization and the conveyance of smaller-stakes and possession-based transactions, as well as when transacting purely virtual assets. For similar reasons, applications to registries of rights hinge on restricting their numerus clausus and any risk endangering indefeasibility. 


\section{REFERENCES}

Abadi, Joseph, and Markus Brunnermeier. 2018. "Blockchain Economics.” NBER Working Paper 25407.

Abramowicz, Michael. 2016. “Cryptocurrency-Based Law.” Arizona Law Review 58(2): 359-420.

Allessie David, Maciej Sobolewski and LorenzioVaccari (Francesco Pignatelli, ed.) 2019. Blockchain for digital government, JCR Science for Policy Report, EUR 29677 EN, Publications Office of the European Union, Luxembourg, JRC115049. http://publications.jrc.ec.europa.eu/repository/bitstream/JRC115049/jrc115049_e_b lockchain_for_digital_government.pdf, visited May 26, 2019.

Andreessen, Marc. 2014. “Why Bitcoin Matters.” New York Times, January 21. http://dealbook.nytimes.com/2014/01/21/why-bitcoin-matters, visited April 25, 2019.

Antelo, Fátima. 2019. “Assessing Blockchain Solutions for Land Title Institutions.” Unpublished Doctoral dissertation, Barcelona: Pompeu Fabra University.

Arruñada, Benito, and Xosé Henrique Vázquez. 2006. "When Your Contract Manufacturer Becomes Your Competitor.” Harvard Business Review 84(9):13545.

Arruñada, Benito, Miguel Espinosa and Luis Garicano. 2018. "Blockchain: The Birth of Decentralized Governance.” April 10. Pompeu Fabra University, Economics and Business Working Paper Series, 1608. https://ssrn.com/abstract=3160070 visited April 25, 2019.

Arruñada, Benito. 2002a. “A Transaction Cost View of Title Insurance and its Role in Different Legal Systems.” The Geneva Papers on Risk and Insurance-Issues and Practice 27(4):582-601.

Arruñada, Benito. 2002b. “The Quasi-Judicial Role of Large Retailers: An Efficiency Hypothesis of their Relation with Suppliers.” In Eric Brousseau and Jean-Michel Glachant, eds., The Economics of Contracts: Theories and Applications. Cambridge: Cambridge University Press, pp. 337-57.

Arruñada, Benito. 2003. "Property Enforcement as Organized Consent.” Journal of Law, Economics, and Organization 19(2):401-44.

Arruñada, Benito. 2007a. "Pitfalls to Avoid when Measuring the Institutional Environment: Is ‘Doing Business’ Damaging Business?” Journal of Comparative Economics 35(4):729-47.

Arruñada, Benito. 2007b. "Market and Institutional Determinants in the Regulation of Conveyancers.” European Journal of Law and Economics 23(2):93-116.

Arruñada, Benito. 2010a. "Institutional Support of the Firm: A Theory of Business Registries.” The Journal of Legal Analysis 2(2):525-76.

Arruñada, Benito. 2010b. “Leaky Title Syndrome?” New Zealand Law Journal 115-20. 
Arruñada, Benito. 2012. Institutional Foundations of Impersonal Exchange: Theory and Policy of Contractual Registries. Chicago: University of Chicago Press.

Arruñada, Benito. 2017. "Property as Sequential Exchange: The Forgotten Limits of Private Contract.” Journal of Institutional Economics, 13(4):753-83.

Arruñada, Benito. 2018. “Blockchain’s Struggle to Deliver Impersonal Exchange.” Minnesota Journal of Law, Science \& Technology 2018(19):55-105.

Baker, Karl. 2018. "Delaware Eases Off Early Blockchain Zeal after Concerns over Disruption to Business.” Delaware Online-The News Journal, February 2, https://eu.delawareonline.com/story/news/2018/02/02/delaware-eases-off-earlyblockchain-zeal-after-concerns-over-disruption-business/1082536001/, visited April 28, 2018.

Biais, Bruno, Christophe Bisière, Matthieu Bouvard, and Catherine Casamatta. 2019. “Blockchains, Coordination, and Forks.” AEA Papers and Proceedings 109:88-92.

Buterin, Vitalik. 2017. “Notes on Blockchain Governance.” Vitalik Buterin's website, December 17, https://vitalik.ca/general/2017/12/17/voting.html, visited June 14, 2019.

Casey, Anthony J., and Anthony Niblett. 2017. “Self-Driving Contracts.” Journal of Corporation Law 42(1):101-31.

Catalini, Christian, and Joshua S. Gans. 2016. "Some Simple Economics of the Blockchain”. NBER Working Paper 22952.

Cooter, Robert, and Thomas Ulen. 2016. Law and Economics, $6^{\text {th }}$ edition. Berkeley Law Books, http://scholarship.law.berkeley.edu/books/2, visited April 25, 2019.

Cooter, Robert, Lewis Kornhauser, and David Lane. 1979. "Liability Rules, Limited Information, and the Role of Precedent.” Bell Journal of Economics 10(1):366-73.

Da Costa Cruz, Janina, Aenne Sophie Schröder and Georg von Wangenheim. 2019. "Chaining Property to Blocks-On the Economic Efficiency of Blockchain-Based Property Enforcement.” In Witold Abramowicz and Adrian Paschke (eds.), 2018 Business Information Systems Workshops, Berlin: Springer, pp. 313-24.

De Soto, Hernando, Enrique Ghersi, Mario Ghibellini, and Instituto Libertad y Democracia. 1986. El otro sendero: la revolución informal. Lima: El Barranco. (English ed.: De Soto, Hernando. 1989. The Other Path: The Invisible Revolution in the Third World. New York: Harper \& Row).

DeMartino, Ian. 2016. “As Ethereum Classic Forks, DAO Hacker Moves Funds.” Inside Bitcoin, October 25, https://insidebitcoins.com/news/ethereum-classic-forksdao-hacker-moves-funds/36505, visited April 25, 2019.

Evans, David S. 2014. "Economic Aspects of Bitcoin and Other Decentralized PublicLedger Currency Platforms.” University of Chicago, Coase-Sandor Institute Institute for Law \& Economics, Working Paper 685, April. https://ssrn.com/abstract=2424516, visited April 25, 2019.

Gallego Fernández, Luis Antonio. 2017. “Blockchains and Title Registration.” IPRACINDER International Review 1:26-51. 
Gans, Joshua S. 2019. “The Fine Print in Smart Contracts.” NBER Working Paper 25443.

Goldman Sachs. 2016. Profiles in Innovation: Blockchain-Putting Theory Into Practice. Goldman Sachs Group, Inc., New York, May 24. https://pgcoin.tech/wpcontent/uploads/2018/06/blockchain-paper.pdf, visited April 25, 2019.

Graglia, J. Michael, and Christopher Mellon. 2018. "Blockchain and Property in 2018: At the End of the Beginning.” Innovations: Technology, Governance, Globalization 12(1-2):90-116.

Griggs, Lynden, Rod Thomas, Rouhshi Low and James Scheibner. 2017. "Blockchains, Trust and Land Administration: The Return of Historical Provenance.” Property Law Review 6(3):179-94.

Hadfield, Gillian K., and Iva Bozovic. 2016. "Scaffolding: Using Formal Contracts to Support Informal Relations in Support of Innovation.” Wisconsin Law Review, 5, 981-1032.

Hansmann, Henry, and Reinier Kraakman. 2002. "Property, Contract, and Verification: The Numerus Clausus Problem and the Divisibility of Rights.” Journal of Legal Studies 31(2):S373-S420.

Harris, Ron. 2000. Industrializing English Law: Entrepreneurship and Business Organization, 1720-1844. Cambridge University Press: Cambridge.

Hobson, Dominik. 2016. “Case study - Corporate actions.” In Mark Walport, ed., Distributed Ledger Technology: Beyond Block Chain. London: Government Office for Science, January, pp. 58-59.

Holden, Richard, and Anup Malani. 2018. "Can Blockchains Solve the Holdup Problem in Contracts.” Becker-Friedman Institute, Chicago, Working Paper 2018-12, February. https://bfi.uchicago.edu/wp-content/uploads/WP_No.2018-12.pdf, visited May 4, 2019.

ISDA (International Swaps and Derivatives Association). 2016. "The Future of Derivatives Processing and Market Infrastructure.” ISDA Whitepaper, September, https://www2.isda.org/attachment/ODcwMA==/Infrastructure\%20white\%20paper. pdf, visited April 25, 2019.

Kempe, Magnus, ed. 2016. “The Land Registry in the Blockchain: A Development Project with Lantmäteriet (The Swedish Mapping, Cadastre and Land Registration Authority), Telia Company, ChromaWay and Kairos Future.” White Paper, July. Stockholm: Kairos Future.

Kempe, Magnus, ed. 2017. "The Land Registry in the Blockchain-Testbed: A Development Project with Lantmäteriet, Landshypothek Bank, SBAB, Telia company, ChromaWay and Kairos Future.” March. Stockholm: Kairos Future.

Kiviat, Trevor I. 2015. "Beyond Bitcoin: Issues in Regulating Blockchain Transactions.” Duke Law Journal 65(3):569-608.

Klein, Benjamin, and Keith B. Leffler. 1981. "The Role of Market Forces in Assuring Contractual Performance.” Journal of Political Economy 89(4): 615-41. 
Larimer, Daniel. 2018. “The 'Intent of Code’ is Law.” Medium, June 27. https://medium.com/@bytemaster/the-intent-of-code-is-law-c0e0cd318032, visited June 9, 2019.

Lehdonvirta, Vili. 2016. “The Blockchain Paradox: Why Distributed Ledger Technologies May Do Little to Transform the Economy,” Policy and Internet Blog, November 21, http://blogs.oii.ox.ac.uk/policy/the-blockchain-paradox-whydistributed-ledger-technologies-may-do-little-to-transform-the-economy, visited April 25, 2019.

Lessig, Lawrence. 1999. Code, and Other Laws of Cyberspace. Basic Books: New York.

Lessig, Lawrence. 2006. Code: Version2.0. Basic Books: New York.

Levin, Jonathan. 2003. "Relational Incentive Contracts.” American Economic Review 93(3): 835-57.

Lifthrasir, Ragnar. 2017. "Permissionless Real Estate Title Transfers on the Bitcoin Blockchain in the USA! — Cook County Blockchain Pilot Program Report.” Medium, June 28, https://medium.com/@RagnarLifthrasir/permissionless-realestate-title-transfers-on-the-bitcoin-blockchain-in-the-usa-5d9c39139292, visited April 25, 2019.

Lomas, Natasha. 2015. "Everledger Is Using Blockchain To Combat Fraud, Starting With Diamonds,” Tech Crunch, June 29. https://techcrunch.com/2015/06/29/everledger/, visited April 25, 2019.

Merrill, Thomas W., and Henry E. Smith. 2000. "Optimal Standardization in the Law of Property: The Numerus Clausus Principle.” Yale Law Journal 110(1):1-70.

Moore, John. 1992. "Implementation, Contracts, and Renegotiation in Environments with Complete Information.” In J.-J. Laffont, ed., Advances in Economic Theory: Invited Papers to the World Congress of the Econometric Society, vol. I:182-281.

Narayanan, Arvind, Joseph Bonneau, Edward Felten, Andrew Miller \& Steven Goldfeder. 2016. Bitcoin and Cryptocurrency Technologies: A Comprehensive Introduction, Princeton University Press: Princeton.

Ortolani, Pietro. 2016. "Self-Enforcing Online Dispute Resolution: Lessons from Bitcoin.” Oxford Journal of Legal Studies 36(3): 595-629.

Ortolani, Pietro. Forthcoming. "The Impact of Blockchain Technologies and Smart Contracts on Dispute Resolution: Arbitration and Court Litigation at the Crossroads." Uniform Law Review.

Posner, Richard A. 1973/2007. The Economic Analysis of Law. 7th ed. New York, NY: Aspen Publishers.

Richman, Barak D. 2009. "Ethnic Networks, Extralegal Certainty, and Globalisation: Peering into the Diamond Industry.” In Volkmar Gessner, ed., Contractual Certainty in International Trade: Empirical Studies and Theoretical Debates on Institutional Support for Global Economic Exchanges. Oxford: Hart Publishing, 31-49. 
Rose, Carol M. 1988. "Crystals and Mud in Property Law.” Stanford Law Review 40(3):577-610.

Scholz, Lauren Henry. 2017. “Algorithmic Contracts.” Stanford Technology Law Review 20(2):128-69.

Sehra, Avtar. 2016. "Building and Decentralised Ecosystem.” ETC London Meetup, August 18, 2016. http://www.slideshare.net/arcatomia/ethereum-classic-18-august2016, visited April 25, 2019.

Shapiro, Carl. 1983. "Premiums for High Quality Products as Returns to Reputations.” Quarterly Journal of Economics 98(4):659-79.

Shavell, Steven. 2004. Foundations of Economic Analysis of Law, Harvard University Press: Cambridge, MA.

Shea, Ryan. 2016. "Simple Contracts are Better Contracts: What We Can Learn from the Meltdown of The DAO.” Medium. June 17, https://medium.com/@ryanshea/simple-contracts-are-better-contracts-what-wecan-learn-from-the-dao-6293214bad3a, visited April 25, 2019.

Surden, Harry. 2012. “Computable Contracts.” University of California Davis Law Review 46(2):629-700.

Szabo, Nick. 1997. “The Idea of Smart Contracts.” Nick Szabo’s Papers and Concise Tutorials.

http://www.fon.hum.uva.nl/rob/Courses/InformationInSpeech/CDROM/Literature/ LOTwinterschool2006/szabo.best.vwh.net/idea.html, visited April 25, 2019.

Szabo, Nick. 1998-2005. "Secure Property Titles with Owner Authority.” http://www.fon.hum.uva.nl/rob/Courses/InformationInSpeech/CDROM/Literature/ LOTwinterschool2006/szabo.best.vwh.net/securetitle.html, visited April 25, 2019.

Tapscott, Don, and Alex Tapscott. 2016. Blockchain Revolution: How the Technology Behind Bitcoin Is Changing Money, Business, and the World. Penguin: New York.

Tashea, Jason. 2019. "Wyoming and Vermont Hope to Attract Tech Entrepreneurs by Passing Laws Favorable to Blockchain.” ABA Journal, March 1. http://www.abajournal.com/magazine/article/blockchain-wyoming-vermontregulations-laws, visited May 15, 2019.

Taylor, Simon. 2016. “Definitions.” In Mark Walport, ed., Distributed Ledger Technology: Beyond Block Chain. London: Government Office for Science, January, pp. 17-18.

Thomas, Rod, Rouhshi Low, and Lynden Griggs. 2012. “Land Fraud and Inappropriate Dealings in an Electronic Environment: An Australian and New Zealand Perspective.” Paper presented at the $11^{\text {th }}$ Australasian Property Law Teachers Conference, 12-13 July, National University of Singapore.

https://eprints.qut.edu.au/51014/2/51014.pdf, visited May 25, 2019.

Thomas, Rod. 2017. "Blockchain’s Incompatibility for Use as a Land Registry: Issues of Definition, Feasibility and Risk.” European Property Law Journal 6(3):361-90. 
Tombs, Lauren. 2019. “Could Blockchain Be the Future of the Property Market?” HM Land Registry Blog, 24 May. https://hmlandregistry.blog.gov.uk/2019/05/24/couldblockchain-be-the-future-of-the-property-market/, visited June 4, 2019.

Vermont Secretary of State. 2019. Blockchains for Public Recordkeeping and for Recording Land Records. A White Paper of the Vermont State Archives and Records Administration. January $15^{\text {th }}$.

Voloshyn, Alexander. 2018. "First Government Sanctioned Blockchain Recorded Real Estate Deal in the US.” Medium, 21 March 2018. https://medium.com/propy/firstgovernment-sanctioned-blockchain-recorded-real-estate-deal-in-the-usbb83e8292a7f, visited April 25, 2019.

Walport, Mark, ed. 2016. Distributed Ledger Technology: Beyond Block Chain. London: Government Office for Science, January.

https://www.gov.uk/government/uploads/system/uploads/attachment_data/file/492 972/gs-16-1-distributed-ledger-technology.pdf, visited April 25, 2019.

Williamson, Oliver E. 1985. The Economic Institutions of Capitalism, The Free Press, New York.

Yarbrough, Karen A. 2017. Blockchain Pilot Program Final Report, Cook County Recorder of Deeds, Chicago, May 30, http://cookrecorder.com/wpcontent/uploads/2016/11/Final-Report-CCRD-Blockchain-Pilot-Program-forweb.pdf, visited April 14, 2019. 
Figure 1. Some possibilities and examples for the application of blockchain to real property

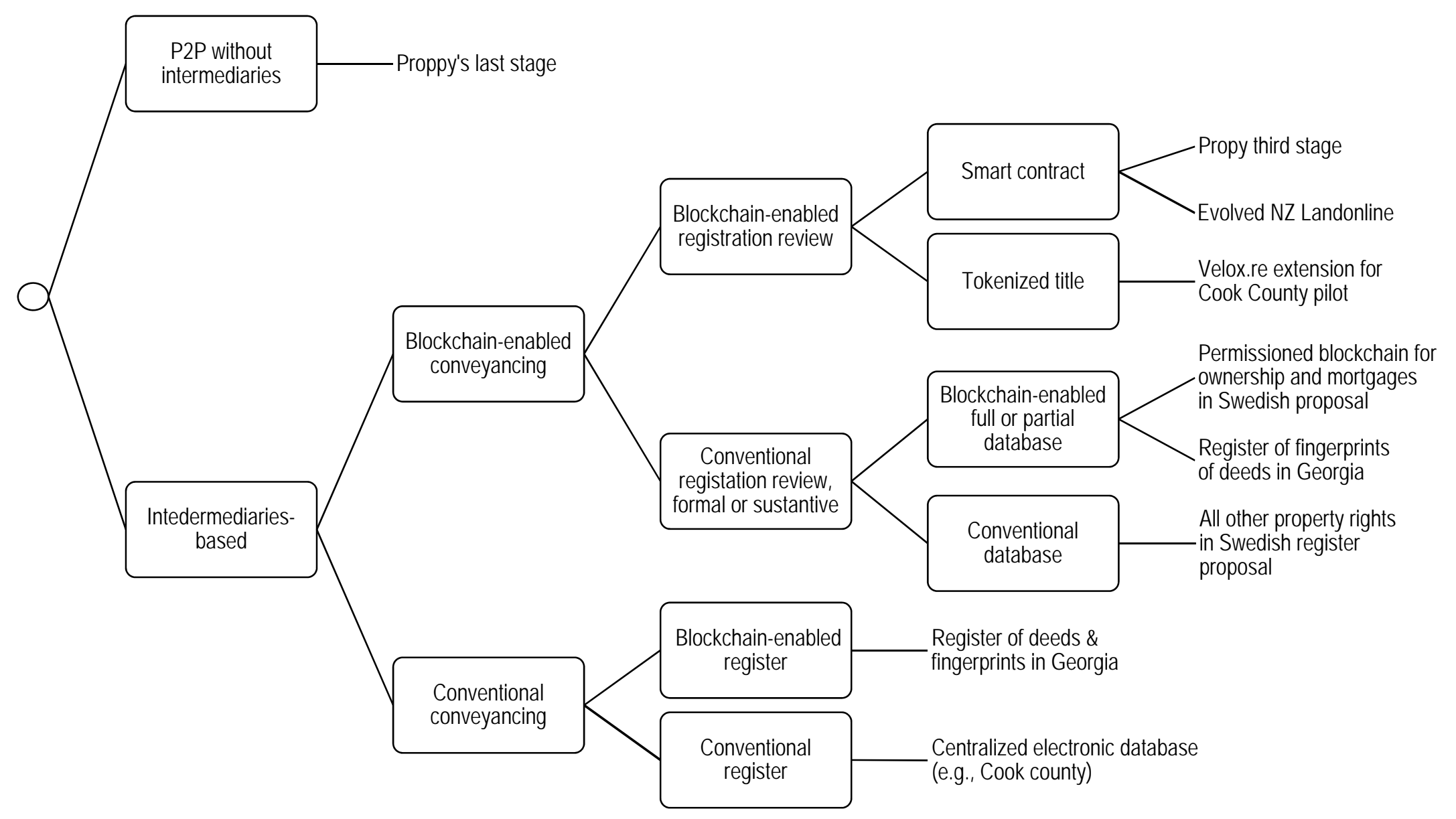

